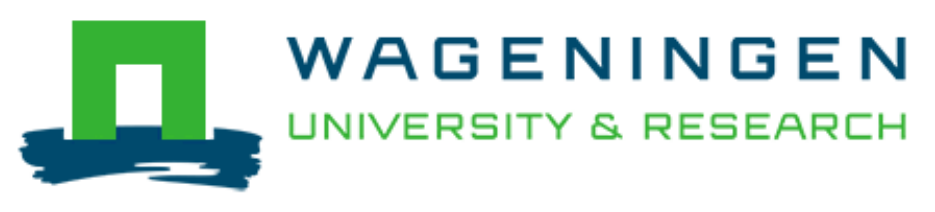

Vulnerability assessments as a political creation: Tsunami management in Portugal

Pronk, M., Maat, H., \& Crane, T. A.

This article is made publically available in the institutional repository of Wageningen University and Research, under article 25fa of the Dutch Copyright Act, also known as the Amendment Taverne.

Article $25 \mathrm{fa}$ states that the author of a short scientific work funded either wholly or partially by Dutch public funds is entitled to make that work publicly available for no consideration following a reasonable period of time after the work was first published, provided that clear reference is made to the source of the first publication of the work.

For questions regarding the public availability of this article, please contact openscience.library@wur.nl.

Please cite this publication as follows:

Pronk, M., Maat, H., \& Crane, T. A. (2017). Vulnerability assessments as a political creation: Tsunami management in Portugal. Disasters, 41(4), 728-747.

https://doi.org/10.1111/disa.12223 


\title{
Vulnerability assessments as a political creation: tsunami management in Portugal
}

\author{
Maartje Pronk Programme Officer, Lepra, United Kingdom, Harro Maat Assistant \\ Professor, Knowledge, Technology and Innovation Group, Wageningen University, \\ Netherlands, and Todd A. Crane Senior Scientist, Livestock Systems and Environment, \\ International Livestock Research Institute, Kenya
}

Vulnerability assessments are a cornerstone of contemporary disaster research. This paper shows how research procedures and the presentation of results of vulnerability assessments are politically filtered. Using data from a study of tsunami risk assessment in Portugal, the paper demonstrates that approaches, measurement instruments, and research procedures for evaluating vulnerability are influenced by institutional preferences, lines of communication, or lack thereof, between stakeholder groups, and available technical expertise. The institutional setting and the pattern of stakeholder interactions form a filter, resulting in a particular conceptualisation of vulnerability, affecting its operationalisation via existing methods and technologies and its institutional embedding. The Portuguese case reveals a conceptualisation that is aligned with perceptions prevalent in national government bureaucracies and the exclusion of local stakeholders owing to selected methodologies and assessment procedures. The decisions taken by actors involved in these areas affect how vulnerability is assessed, and ultimately which vulnerability reduction policies will be recommended in the appraisal.

Keywords: risk management, social mediation, tsunami, vulnerability assessment

\section{Introduction}

The conceptualisation and the measurement of vulnerability have become increasingly popular topics in disaster studies and risk management. There has been a major shift in the conceptualisation of disasters and risks since the I980s. The 'traditional' approach to risk management that held sway until then was hazard-oriented, focusing on the physical cause of a disaster, such as an earthquake or storm. Consequently, risks were dealt with by proposing technical solutions, typically the enhancement or construction of infrastructural works (Birkmann, 2006). To go beyond the limits of the hazard-oriented approach, the notion of vulnerability was introduced to address the question of why certain communities or environments are more susceptible to harm than are others. In addition to technical and physical factors, social factors are key in determining vulnerability and in managing risk (Birkmann, 2006). Differences between conceptualisations of vulnerability relate to the way in which social factors are incorporated, but there is overall agreement among scholars that vulnerability 
arises from cultural, economic, political, and social contexts that influence both susceptibility to hazards and the capacity to respond to them (Cutter, Boruff, and Shirley, 2003; Wisner et al., 2004; Birkmann, 2006).

Vulnerability assessments play a vital role in risk management. Crucial to current notions of vulnerability is not only the level of susceptibility of certain communities but also their capacity to anticipate, respond to, and recover from the impacts of a disaster. The development of an appropriate methodology and the proper implementation of a vulnerability assessment thus generate valuable information that national, regional, and local governments can use to define and implement appropriate measures to decrease susceptibility and to increase the coping capacity of people exposed to certain hazards and risks. Given the richness of the vulnerability literature, there is ample choice of factors and indicators to include in a vulnerability assessment. The task of the vulnerability researcher, therefore, is to create or select an instrument that includes all relevant factors and fits the context of application. Methodological choices made in vulnerability assessments can have profound effects on the policy recommendations and strategies that emerge from them. The identification of vulnerability, its description in research, and its inscription in policy all imply particular actions and interventions through risk management policy (Ribot, 20I4). Hence the methodological choices made in vulnerability assessments have consequences for the insights and information that enter the process of policymaking and policy implementation.

This paper argues that the development and application of vulnerability assessments are politically filtered: some elements are excluded whereas others are included. An analysis of a Portuguese tsunami vulnerability reduction project is used to illustrate this process. The example at hand shows that political filtering happens through the interactions between research institutes and governmental agencies involved in the vulnerability assessment. It revealed that political manoeuvring within research groups and their interactions with policy agencies created a disciplinary divide, favouring physical indicators and leaving out most socioeconomic components of the vulnerability assessment. By filtering out the 'human' side of vulnerability, policies based on the outcomes of the assessment will be ill-informed and misguided in mobilising available human resources to deal with tsunami risks effectively. The political filtering process reduces especially opportunities for local risk management professionals and community organisations to get involved in vulnerability assessment and in developing vulnerability reduction measures.

First the study reviews how vulnerability assessments get filtered, resulting in a conceptual model that aids understanding of how political filtering occurs in the development of a vulnerability assessment. Next the methodology is explained and the case study is introduced. The following results section shows how the vulnerability assessment in Portugal was filtered, producing a particular conceptualisation and affecting the operationalisation and institutional embedding of the vulnerability assessment. The subsequent discussion section looks at the position of the case study project within a broader debate on assessments as technologies of governance. The paper concludes that vulnerability assessments are not apolitical tools of disaster management, but rather are filtered owing to the subjective choices of the actors involved. 


\section{A framework for evaluating assessments}

The vulnerability approach has gradually replaced the hazard-oriented approach in disaster studies; the current understanding is that vulnerability emerges from interrelated cultural, economic, environmental, political, and social processes (Birkmann, 2006; Nelson, Adger, Brown, 2007; Cutter, 20II). Vulnerability indicates a community's susceptibility to catastrophic outcomes should a hazardous event occur. It is, therefore, a socially mediated link between a hazard and a disaster: it determines whether a hazardous event turns into a disaster and the severity of its impact.

Social vulnerability highlights the social determinants of vulnerability. Differences between community members' social characteristics, such as class, disaster experience, ethnicity, gender, or social capital, contribute to differences in vulnerability. Although there is overall consensus on the social factors affecting vulnerability (Cutter, Boruff, and Shirley, 2003), the complexity of interactions through which social vulnerability takes shape gives rise to multiple perspectives (Oliver-Smith, I999). There are, however, several shared principles. First, a point on which most scholars agree is an individual's reflexive agency, implying that people are not merely exposed to risks and become victims of disasters but that they participate actively in prevention, mitigation, or reconstruction. For Wisner et al. (2004, p. II), human agency is central to their understanding of vulnerability, which they define as the characteristics of people and their situations that 'influence their capacity to anticipate, cope with, resist and recover from the impact of a natural hazard'. Second, the inclusion of human agency in vulnerability approaches has implications for the perception of the biophysical components of vulnerability. Owing to people's active engagement, the biophysical environment becomes socially mediated or socially constructed (Fuchs, Birkmann, and Glade, 20I2; Birkmann et al., 20I3). Third, perspectives generally coincide with different spheres or scales of social interaction. Birkmann (2006) presents a set of four widening conceptual spheres, each covering an increasing quantity of social processes and interactions. More encompassing conceptualisations require a more wide-ranging analytical instrument with which to understand the complexity underlying vulnerability. Conceptual choices based on these shared principles will have consequences for the type of work to be done when applied in a vulnerability assessment.

An assessment instrument to analyse vulnerability is based on three key choices: researchers may use one created by others; adjust one as required; or develop one themselves. Any instrument has to match case-specific features, which can imply the characteristics of a situation or specific social phenomena. Preliminary research may be required, so as to include, for instance, 'indigenous interpretations' of extreme events and hazards in an instrument (Wisner et al., 2004, p. I23). Another important concern is the size and scope of datasets. The more detailed information to be collected, the more data to be processed and analysed. More comprehensive models may result in certain data being unavailable or being very costly to generate (Birkmann et al., 20I3). Hinkel (2OII) characterises these and other considerations in vulnerability assessment instruments as deductive, inductive, normative, and non-substantial arguments. The latter refers to issues unrelated to vulnerability, such as the given 
example of dataset size. Focusing on climate change vulnerability, Hinkel (20I I, p. 204) concludes that most assessment instruments are not very functional owing to 'a lack of specificity about the purposes of assessing vulnerability' in policy documents and the academic literature. This general lack of specificity perhaps has a more specific cause. The case study presented in this paper suggests that political choices within the research and policy environments deserve more attention as a major cause of ineffective vulnerability assessments.

Most vulnerability assessments aim to address particular policy questions. The complexity of vulnerability factors has to be translated therefore into an ordered set of parameters that can be understood by policymakers and planners (McLaughlin and Cooper, 20Io, p. 234). Interactions with policymakers and governing bodies affect a vulnerability assessment from the outset, not only during the process of translating the results into adaptation strategies and interventions. The political processes behind vulnerability research itself have received little attention so far. Vulnerability assessments involve multiple actors who select approaches, develop tools, and apply methods. In the course of this work, value judgements may lose their visibility as normative choices often are hidden in what may seem to be an objective vulnerability assessment. Fuchs (2009) created a model in which an individual's perception of vulnerability is filtered initially by cultural conditions and then by communication between individuals, groups, and institutions. Vulnerability research, he argues, has to include the filtered perceptions of actors because they affect how vulnerability is evaluated and what measures are taken (Fuchs, 2009).

This paper begins with the assumption that researchers are not exempt from having filtered perceptions. Whereas Fuchs applied the perception filter to community members who experience vulnerability, this study applies it to researchers' experiences in creating vulnerability assessments themselves. In the process of establishing a research instrument, choices regarding what and who to include have a direct bearing on the scope and the effectiveness of vulnerability assessment research. These deliberations take place within and between research institutes, as well as in the interaction between science and policy. The filter (see Figure I) thus demarcates a social space of interaction between researchers and policymakers representing different groups, institutes, and governmental bodies. Conceptual, instrumental, and institutional considerations pass through the filter when creating an assessment instrument and the results of the assessment are filtered again before ending up in policy recommendations and proposed measures.

In creating an assessment study, conceptual considerations, specific features of the study area, research practicalities, and research team composition are all interrelated. Research institutes may have a particular preference for certain conceptual frameworks that match their research capacity. For example, a hazard-oriented conceptualisation emphasising the physical manifestations of vulnerability is better served by an institute that has the instruments and the capacity to measure them. Such institutes also may have the capacity to design infrastructural and engineering solutions. Institutes with primarily social science capacities typically will address 
Figure 1. The filtering of a vulnerability assessment

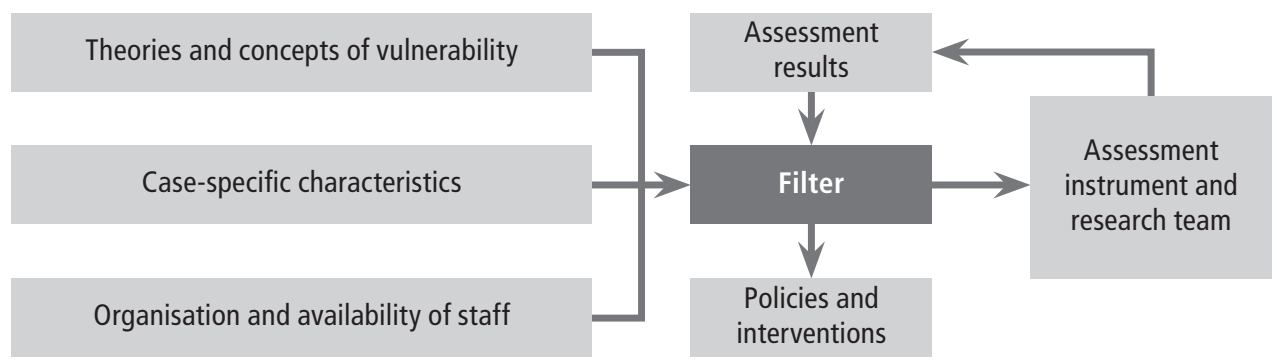

Source: authors.

human agency and the socially mediated character of the physical environment. Moreover, the scope of certain conceptual frameworks has implications for the methods selected. Vulnerability research from a political-ecology perspective, for instance, prefers community-based participatory approaches to capture elements of self-evolution and self-organisation that are vital for recovery and risk reduction (Oliver-Smith, 2005). In sum, pre-existing information on the phenomenon to be assessed, practical concerns, and the availability of particular tools inform the choices made during conceptualisation.

The institutional location of the assessment is an important factor in the filtering of a vulnerability assessment. The selections made, in terms of how vulnerability is defined or how it is assessed, are predetermined in part by the way in which vulnerability assessments are institutionally embedded. This has two implications. First, the assessment process is affected by (internal) institutional politics. For example, Jasanoff (I999) concludes that questions at the heart of risk studies about agency, causation, and uncertainty are deeply embedded in cultural values and beliefs present in the institutional environment. Moreover, institutional embedding affects which actors and knowledge are included in the assessment process. Besides what has been said about institutional traditions and capacities affecting the conceptualisation and operationalisation of vulnerability, social actors frequently are organisations, social groups, or companies. There might be existing forms of cooperation or connections between certain organisations or isolation and distrust. In each organisation, particular views and perceptions dominate, often referred to as the institutional culture. To paraphrase the seminal work of Douglas (I986), what seem to be individual decisions are mostly an effect of how institutions think. Hence the institutional setting is an important factor in the shaping of vulnerability assessments.

Consequently, vulnerability assessments clearly are not neutral or one-size-fits-all methodologies that can be applied similarly in all contexts. What theories and concepts are used, which physical and social characteristics are included, and how the vulnerability assessment is institutionally embedded are the outcomes of a process in which appropriate options, available ideas, instruments, and the selection of research teams are politically filtered. 


\section{Background and methodology}

The Portuguese coast is vulnerable to tsunamis (Birkmann et al., 20Io). The last recorded tsunami was in 1755 when an earthquake in the Atlantic Ocean impacted the Portuguese coast (Chester and Chester, 20I0). The periodicity of the event is estimated at 250 years, explaining recent initiatives to carry out a vulnerability assessment (tsunami risk) of the Portuguese coast (Universidade de Coimbra and Câmara Municipal da Figueira da Foz, 20IO).

The case study presented here is the TSURIMA project, a joint research endeavour between the University of Lisbon and the University of Coimbra in Portugal. It sought to develop a tsunami vulnerability assessment and management methodology for four locations in the country. The University of Lisbon created tsunami propagation models, while a team from the University of Coimbra conducted geographic information system (GIS) evaluations of social vulnerability to tsunami risk. As this paper relates to vulnerability research, it focuses on the work of the Coimbra team.

The TSURIMA project was a scientific research venture with the specific objectives of being interdisciplinary and policy-oriented, yielding a good opportunity to investigate how different actors make choices in the creation and execution of a vulnerability assessment. Research was performed in spring 20I3, while the TSURIMA project was in its initial phases, and in just one project location: Figueira da Foz, a coastal city and municipality at the mouth of the Mondego River in the Coimbra district of Portugal. At this time the assessment was still a work in progress and its outlines were under construction. The social processes of conceptual and methodological development were thus ongoing and clearly visible.

Figueira da Foz is a town with some 62,000 residents located on the shore of the Atlantic Ocean about 200 kilometres north of Lisbon (Instituto Nacional de Estatística, 20II). Risks to the town are addressed by policy bodies at the regional and national level. At the local level, professionals with the Protecção Civil (Civil Protection), a municipal authority that combines the fire brigade, police force, Red Cross, the local forestry department, and the city council, implement risk management.

The data presented here were collected by the first author using a mixed-methods approach, involving document analysis, key informant interviews, and participant observation in relevant organisations and processes. Eleven semi-structured interviews were held with primary TSURIMA scientists, policymakers, and risk management professionals. Through participant observation, information was gathered from meetings of the TSURIMA team to develop the assessment index and during data collection by researchers performing the vulnerability assessment. While following the TSURIMA team, additional respondents were selected for interview. All interviews (except for one done by e-mail) took place at the location and lasted for at least one hour. Interview questions covered risk perceptions, experience of disasters, interdisciplinarity, learning experiences, and definitions of (social) vulnerability. Besides the TSURIMA research team, data were collected through participatory observation and informal interviews with representatives of two principal institutions: 
the Protecção Civil; and the Red Cross. The observations concentrated on the interactions between these local actors and their views on tsunami risk management. As the research centred mainly on the work of the Coimbra team, observation of the Lisbon team remained limited to moments of interaction between them. The interviews were recorded and analysed using ATLAS-ti software. Finally, the literature used by TSURIMA scientists to develop their assessment and related literature on risk management policies relevant to the project were reviewed.

\section{The TSURIMA project: outcomes and results}

Measuring and mapping vulnerability sounds like a neutral first step in vulnerability reduction. It is an appealing idea to track down vulnerability, jot it on a map, and use the map to develop risk management strategies. The evolution of the TSURIMA project shows that it is not that simple. From the outset there were several decisions to be made by various actors, all with different opinions. This paper looks first at how the TSURIMA scientists perceived and conceptualised vulnerability. Next it examines some key elements of the process and the technologies that the scientists employed to translate their understanding of vulnerability into an assessment. Finally, it shows how the project was shaped by interaction with risk management policy.

\section{Conceptualisation of vulnerability}

Defining vulnerability necessitates making claims about a specific set of relationships: the vulnerability of a certain system to a certain threat because of certain factors. A definition frames these relationships, and thereby embodies certain perceptions and approaches (Green and McFadden, 2007). The lack of a common definition of vulnerability or a universal approach for evaluating vulnerability meant that the TSURIMA scientists had to make choices about what constitutes vulnerability in their assessment of Figueira da Foz. The understanding that vulnerability is the product of many interrelated processes leads to the conclusion that research needs to incorporate different scientific disciplines to gauge and reduce vulnerability successfully (Cardona, 2004b, in Birkmann, 2006). The TSURIMA project team included geographical and numerical modellers, sociologists, and economists. Ideally this would generate a broad and inclusive vulnerability assessment in which different perceptions of vulnerability would result in an approved and common methodology.

The TSURIMA scientists all agreed on the general objective of their research: to improve tsunami risk management policy. The TSURIMA project was very policyconscious, and team members reiterated that they were producing an assessment for use by policymakers. During interviews, each team member expressed different ideas on how the TSURIMA project would benefit policy. One said that the results of the vulnerability assessment would simply be used to educate policymakers about tsunami risk. Another hoped that the project would develop tsunami evacuation procedures in cooperation with policymakers. A third suggested that the research conclusions 
would only be presented to policymakers, who would then decide for themselves whether or not to integrate any of the conclusions into risk policy. Apparently the different viewpoints on the objective of the vulnerability assessment anticipated the use of its results by policymakers. In this way ideas about what policies to develop and implement were mixed into discussions on what conceptualisation of vulnerability and what methodology to utilise.

The way in which differences in perception of the project's objective affected the assessment strategy and methods became explicit in an internal TSURIMA discussion on which part of the initiative is more important: the tsunami model or the vulnerability assessment (see Figure 2)? When talking to Coimbra team members about these meetings, they said that the Lisbon team did not see the vulnerability assessment as important, but rather, as one Coimbra researcher put it, as 'a complement to the tsunami model'. A Lisbon scientist stated that the tsunami model was 'fundamental to establish useful measures for the mitigation of this sort of [tsunami] risk'. Note that only the Lisbon model is referred to as 'fundamental'; the Coimbra contribution is not mentioned. The Coimbra team thus felt unappreciated and perhaps even side-tracked, creating friction and distrust within the project staff.

The process was finalised in 2014 and the Social Vulnerability matrix and algorithm applied were published in 2015 (Barros et al., 2015). Social vulnerability is listed as one of four types of vulnerability, as well as morphological, structural, and taxable property vulnerability. Each type is given equal weight in the Composite Vulnerability Index.

The different perceptions of each other's roles and the different contributions to the project influenced cooperation within the TSURIMA team. The Coimbra scientists had little influence on the tsunami model generated by the Lisbon team. The Coimbra team was not unequivocally supportive of the tsunami model. A key scientist doubted its validity, saying that the model might not take into account all necessary factors. He illustrated his doubt by pointing out that the Lisbon model projects that the Cova Gala hospital will not be affected by a tsunami, even though it is practically

Figure 2. Structure of the TSURIMA project

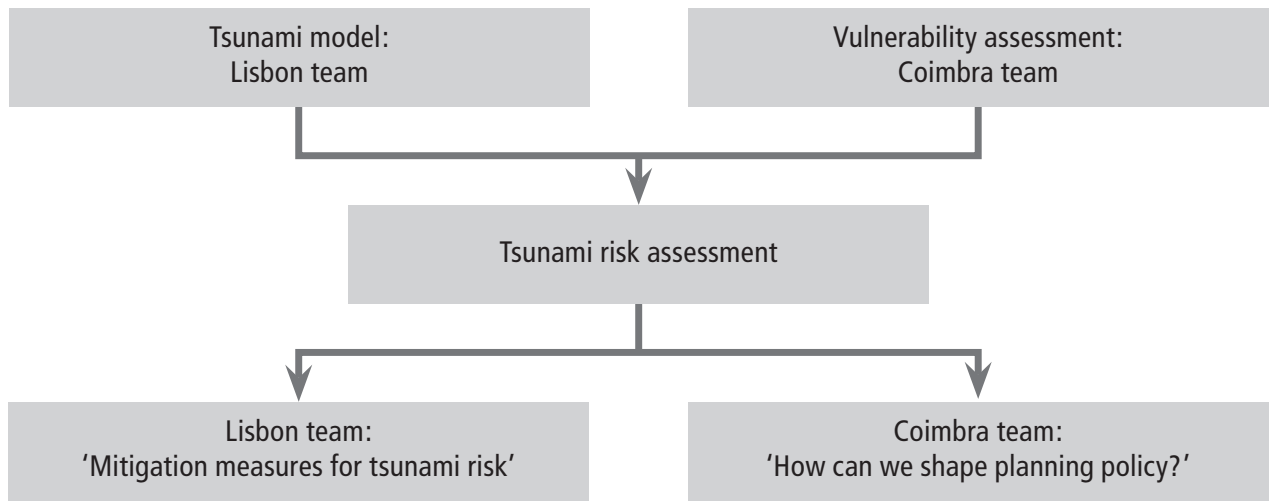

Source: authors. 
located on the beach. A second reason for doubt is that the Lisbon team's tsunami model for Figueira da Foz diverges significantly from models produced by two national agencies, the Autoridade Nacional de Protecção Civil (ANPC) and the Instituto Português do Mar e da Atmosfera (IPMA). Each model has substantially different inundation predictions, according to the Coimbra scientist, who admitted that this has made him feel less confident in his colleagues' model.

Whereas the Coimbra team had little say in the creation of the tsunami model, the Lisbon team was directly involved in the development of the methodology for the vulnerability assessment. The decision was taken to conduct the evaluation by creating a matrix in which different indicators of vulnerability were analysed in five categories, ranging from 'I' (worst-case scenario) to '-I' (best-case scenario). Officially the vulnerability assessment was to be the sole responsibility of the Coimbra team, while the Lisbon team took care of the inundation model. In reality, the Lisbon scientists helped to choose the indicators included in the matrix and even performed the assessment in other project locations. Hence the numerical modelling engineers from Lisbon had an important influence on determining how social vulnerability is appraised. This influence on the social side of the TSURIMA project was remarkable because the responsible engineer lacked knowledge of the social aspects of vulnerability. During one meeting, she said 'I don't understand' each time a theory of social vulnerability was discussed. The engineer particularly objected to the investigation of certain aspects of social vulnerability, such as risk perception and disaster experience, using qualitative methods. She doubted the value of methods that did not produce quantifiable data and said she 'didn't understand' how qualitative data could be part of an assessment. The chosen social vulnerability matrix reflects hesitation in using qualitative indicators, with the use of only quantifiable indicators (Barros et al., 20I5). The major influence of the numerical modelling engineers on the social vulnerability assessment effectively reframed social vulnerability as a concept that should be gauged using measurable quantitative indicators.

All team members agreed that vulnerability is a factor in risk, but they disagreed on the extent and the nature of the relation between vulnerability and risk. This led to discussions on which framework would map vulnerability in such a way as to achieve effective risk management. Eventually the TSURIMA project based its vulnerability assessment for tsunamis on the frameworks of Papathoma et al. (Papathoma and Dominey-Howes, 2003; Papathoma et al., 2003) and Cutter et al. (Cutter, Boruff, and Shirley, 2003; Cutter, 20II). Papathoma's vulnerability assessment has a distinct focus on infrastructural and built environment aspects, which the TSURIMA team believed to be too restrictive. The team chose to complement it, therefore, with indicators based on the work of Cutter, who is more inclusive of the social aspects of vulnerability, such as equity issues. The team settled on an assessment framework that is a direct copy of an assessment framework for social aspects of vulnerability by one of the TSURIMA scientists: the adaptation of Cutter by Mendes (2009), which was developed to determine social vulnerability in the Central Region of Portugal.

TSURIMA's 'field evaluation matrix' used at the time of the authors' research analysed data on: support capacity (education, hospitals, social security facilities, and 
transport options); the presence of fixed or moveable objects; and the characteristics of a building (such as its orientation, the number of windows, or the use of building materials). At this point, the team had not yet decided on the social and economic indicators; although the adaptation of Mendes (2009) was included with 'draft' status. In the final assessment the team chose the following indicators: seasonal occupation; residential urban centres; population dynamics; disadvantaged social contexts; urban areas with commerce; and population dependant on social support (Barros et al., 20I5).

The TSURIMA scientists thus conceptualised vulnerability in such a way that the complex social elements of vulnerability and resilience were excluded. There remained differences in their perceptions of the research objective and of the relative weight of the inundation model versus the vulnerability assessment. These differences were not well discussed or clarified. From the project perspective, the unresolved situation was a good thing, since it allowed all team members to remain involved. At the same time, the resulting conceptualisation process meant that social capital, learning, or social organisation are all left out of the current assessment. TSURIMA's constructions of vulnerability offer little opportunity to include these elements. Key aspects of social vulnerability, such as resilience, social and political networks, social protection, and well-being (see Cannon et al., 2003, in Birkmann, 2006), do not fit within an engineering-based concept of vulnerability. Conceptualisation issues, therefore, are one factor in determining the assessment method, together with operationalisation and institutional location, as the following subsections show.

\section{Process and technology}

The TSURIMA team chose to use GIS to assess social vulnerability. GIS methods allow researchers to include different kinds of data and to translate it into particular projections on geographical maps. As vulnerability is determined by a diverse set of factors, the ability of GIS to express the combined effect of these factors makes it very suitable for vulnerability research (McLaughlin and Cooper, 20I0, p. 233). According to Weichselgartner (200I, p. 89), GIS is 'prompting us to reconsider our understanding of vulnerability', because it allows scientists to make separate maps of different aspects of vulnerability and then to overlay them to create a single vulnerability map.

The making of the assessment index was a key process in the TSURIMA research. The selection of indicators determined which data would be collected and thereby how vulnerability would be evaluated in the project. By including certain indicators and excluding others, actors' methodological choices in the design of an assessment effectively constituted the representation of vulnerability, and by extension the measures that could be taken to reduce it. Indicators act as categories of collected data. Quantitative indicators, however, are socially mediated too, as often they are contested and subject to self-interest, disciplinary biases, or simple misunderstanding (Porter, I995). Furthermore, the decision to emphasise quantifiable indicators precluded the use of important vulnerability (and adaptability) factors that did not lend themselves to quantification. 
The TSURIMA field team collected data for a set of built environment indicators for every building in the tsunami inundation zone. The researchers evaluated how each building scored in relation to the indicators in the assessment matrix, such as building material or number of windows. Scores ranged from 'I' (worst-case scenario) to '-I' (best-case scenario). The data were entered into the GIS software. Secondary sources, such as the national census or datasets of utility companies, were used for the collection of data on social indicators. The same scoring system was employed. The team then combined all of the data on a map of social vulnerability. The complexity of the related social and natural vulnerability factors was reduced to a limited set of 'mappable' indicators. Physical infrastructure and buildings are tangible and have a fixed geographic location. Such data can be processed by GIS software in a rather straightforward manner. Cultural, economic, political, or social aspects of vulnerability usually are less tangible and require a longer route through questionnaires, interviews, or the use of proxy indicators, followed by interpretation of the results and translation into information packages that fit into a GIS model. To measure 'quality of life', for example, the TSURIMA model uses proxies that are tangible and geographically fixed, such as the number of pharmacies in an area or the presence of leisure and sport equipment (Mendes, 2009). But even these proxies were excluded from the final Composite Vulnerability Index (Barros et al., 20I5). Given TSURIMA's engineering-oriented and quantitative understanding of vulnerability, it became especially difficult to include qualitative and socially-oriented data. Consequently, the decision to use GIS methods for the vulnerability assessments shapes what can be examined. The GIS and engineering-dominated nature of TSURIMA has resulted in an assessment framework with an emphasis on quantitative indicators related to physical infrastructure and the built environment.

The Lisbon team decided against using more participatory forms of research. Members of the Coimbra team said that they had proposed to invite local experts to share their knowledge of the community's social vulnerability via Q Methodology. ${ }^{\mathrm{I}}$ This approach was seen as a solution to the lack of secondary data on indicators that were not related to the built environment. Coimbra team members said that the Lisbon team had rejected the suggestion to use Q Methodology. We were unable to identify the reason for the rejection, but the reluctance of the head engineer regarding the use of qualitative data on risk perception (described earlier) may have played a part. Overall, the TSURIMA project does not offer any space to include local knowledge of community members. There is no knowledge exchange between the TSURIMA scientists and the community members of Figueira da Foz. The assessment index did not include any open indicators that could accommodate citizen knowledge.

The TSURIMA assessment did not consider scale and historical context in shaping vulnerability. This is a serious omission. A community's vulnerability builds up over time, making historical context or time a fundamental element in understanding a disaster (Oliver-Smith, I999). Communal history or memory thus represent important alternative variables in TSURIMA's matrix (Oliver-Smith, 2005). The research team decided only to assess indicators at the municipal and local (inundated 
area) level. Regional or global factors in Figueira da Foz's vulnerability, such as the Iberian Peninsula economic crisis or deforestation in Portugal's hinterland, are left out of the assessment. Research has shown that such large-scale factors have serious consequences for local-scale disasters (see, for example, Comfort et al., I999). The work of Delaney et al. (2OI4) also emphasises the relevance of combining the household and national levels in an analysis of vulnerability. The TSURIMA scientists included Cutter's ideas on the importance of social inequality and other social factors in their conceptualisation of vulnerability (Cutter, Boruff, and Shirley, 2003; Cutter, 20II). Nevertheless, the indicators in the vulnerability assessment remained predominantly related to physical infrastructure, the built environment, and the demographic composition of the area. These kind of indicators mostly pertain to physical vulnerability. By depending on these indicators in the research, physical vulnerability comes to determine vulnerability as a whole, leaving little room for social vulnerability. In its understanding of social vulnerability, as well as in relation to the process and technology used to gauge social vulnerability, the TSURIMA project remained very 'engineering-oriented', as one team member put it. It is clear that the decision to develop a quantitative concept of vulnerability was informed in part by the availability of assessment tools, particularly GIS.

\section{Institutional location}

Portuguese risk management policy does not use social vulnerability assessments as a tool in risk reduction or disaster preparation (Mendes, 2009). The exception to this rule is the 20 I Plano Regional do Ordenamento do Território do Centro (PROT), the regional spatial planning policy — some members of the TSURIMA team were involved in creating this regional social vulnerability assessment instrument. The current TSURIMA framework is based on the framework employed in the PROT (described in Mendes, 2009). Hence, social vulnerability assessments are relatively new to Portuguese policymakers and therefore it is relevant to discuss the location of the TSURIMA project within Portuguese risk management policy. The way in which TSURIMA scientists positioned their project with respect to risk management policy and policymakers is also an important socially-mediated process that affects how vulnerability is conceptualised and operationalised.

Risk management falls under spatial planning in Portuguese policy. This categorisation of risk suggests the prevalence of a notion that risk and disaster can be planned and controlled, as is common in the traditional hazard-oriented approach to risk (Birkmann, 2006). One aspect of this approach is that it is more difficult to allow for uncertainty in the policies. This means that TSURIMA likewise feels pressure to eliminate uncertainty from its results if it wants them to be incorporated in policy. Essentially that is the goal of a vulnerability assessment: through its measuring and indexing procedures it reduces risk and vulnerability to simple indicators that eliminate complexity and uncertainty (Hinkel, 20II). What is more, linking risk to spatial planning reinforces the territorial dimension of risk. The TSURIMA project echoed this focus on space by creating a GIS map of tsunami vulnerability. 
Portuguese risk management policymakers and practitioners at all levels of government divided risk into two categories: natural and technological. The former refers to risk caused by natural hazards only, whereas the latter is anthropogenic. The only exception to this categorisation is an outreach flyer by the local Protecção Civil of Figueira da Foz, in which a separate category of 'mixed risk' has been allowed for forest fires. The strict division of risk as either natural or technological is remarkable, because it is generally acknowledged that disasters are always the product of interaction between natural and social factors (Birkmann, 2006). Actors involved in risk management in Figueira da Foz shared this understanding of disasters, as illustrated by the comments of a risk management professional in Figueira da Foz:

In my opinion, 'natural' disasters don't exist. Anthropic disasters exist. An example: if there's an earthquake in the Sahara, the problem for us is zero. If there's a flood in the Amazon forest, for us it gives zero problems. A natural disaster is when you combine humans with nature: then you have a disaster.

Yet, somehow this understanding has not been integrated into policy or management strategies. The strict division of risk in policy had implications for the way in which the TSURIMA team could deal with risk and vulnerability in its assessment. It left little wiggle room for it to come up with vulnerability indicators involving 'mixed' risk factors. There was no possibility for 'and/and' categories. Instead, the TSURIMA project was forced to choose 'either/or' indicators, taking a social or a natural approach to risk.

Coastal risk management in Portugal often is criticised for concentrating on hard infrastructural solutions, both by scientists (see Schmidt et al., 20I3) and by policymakers interviewed in this research. However, policymakers and risk management professionals continued to suggest infrastructural measures, such as building protective sea walls, when they were asked about how to deal with coastal risks. In this institutional context, therefore, it made sense for the TSURIMA project to select the natural/physical approach to vulnerability and to concentrate on built environment indicators. Research with an emphasis on construction and infrastructure matches the policymakers' expectations and wishes, and thus is more likely to be adopted.

Apart from thinking about policymakers' expectations, the TSURIMA team also took into account certain assumptions about policymakers' behaviour when shaping the project. According to the scientists, it is hard to convince policymakers or private sector agents to invest in long-term risk management strategies, as these actors want to see immediate results. So, the team decided to contribute to what it calls 'prevention and proactiveness', which means policies focusing on disaster preparedness and vulnerability reduction rather than on adaptation or resilience. The TSURIMA team translated its objectives very specifically into what one scientist described as 'creating means for an accurate alert system and [. . .] effective evacuation procedures'. The scientists were afraid that if they persisted with long-term strategies, policymakers would simply ignore their advice. 
Political willingness to act is a universal concern in disaster management. Daniels (20I3) shows that for politicians in the United States, it makes more political sense to invest in reactive disaster management strategies than in proactive vulnerability reduction strategies. Helping disaster victims results in more political gain than preventing disasters from occurring, after all. The TSURIMA scientists thus seemed to work as if policymakers were watching over their shoulders. Such hierarchical relations seem to dominate the institutional culture in which the project functioned. There was a strong sense that research should fit with a perception of what policymakers want. Coastal risk management is implemented in Portugal by the Agência Portuguesa do Ambiente, the environmental bodies of local and regional government, by policymakers who have a background in natural sciences and who think in terms of engineering solutions capable of being executed in the short run. This institutional setting preselects a focus on infrastructure to which the TSURIMA team adhered in the conceptualisation and operationalisation of its assessment.

As mentioned, TSURIMA research relied on scientific knowledge and excluded the knowledge of non-scientific experts or locals. This is not a unique situation in Portuguese research or policy. There is a wider context in Portugal of policymakers excluding non-scientific knowledge in their decision-making, at least in risk and environmental policy (Nunes and Matias, 2004a, 2004b; Schmidt et al., 2013). One policymaker said, '[i]n general, the local authorities are not used to involving the local community in this process'. Another added, '[t] hey [citizens] basically don't have any role'. Policymakers, risk management professionals, and scientists all limited the role of citizens in risk management to 'being aware', as they called it. Risk management policies shared this perspective: they only saw a passive role for the public, who needed to be educated by professionals to become aware of risks. For instance, when discussing public participation, the coastal zone policy GIZC (Gestão Integrada da Zona Costeira) went no further than the aim to 'foster commitment and shared responsibility of citizens through the provision of knowledge and technical training' (MAOTDR, 2007, p. 48). Citizens were considered as objects to which knowledge is disclosed, not subjects who participate in the gathering of this knowledge. Such a perspective of community involvement cuts off the role of the community in vulnerability reduction at the level of awareness. This contrasts with most approaches to vulnerability reduction, in which awareness or risk perception are seen as one factor of vulnerability, but certainly not the only factor (see, for example, Eckert et al., 20I2).

\section{Discussion}

Scientific research and policy frequently are mutually constitutive: they work together because scientific research can fill gaps and reduce uncertainty in current policy, thereby justifying this policy (and its makers) as a mode of governance (Jasanoff and Wynne, I998). Vulnerability assessments are becoming an integral tool in risk and disaster reduction policymaking and planning, making them technologies of governance, 
which, through their choices, produce and reproduce certain relationships between policymakers, researchers, and citizens.

Like all technologies, a vulnerability assessment is a tool that is socially mediated. The construction and employment of an assessment implies choices about technologies and about relationships with the world and other actors. This paper, through the case study, has analysed the consequences of this reality. The politics by which research agendas and policy agendas are mutually shaped act as a filter on the creation of vulnerability assessments. The technocratic and built environment solutions of TSURIMA can be seen as representative of the dominant discourse in Western countries that tends to see humans and society as separate from and in control of nature (Oliver-Smith, 2004). It begs the question as to which indicators would be the focus of an assessment matrix developed by a team outside of Europe or North America.

It is relevant to consider how vulnerability assessments originate, because the decisions made in their conceptualisation and operationalisation have serious implications for the disaster and/or risk management strategies that can be derived from these evaluations. A vulnerability assessment that, as in the case of the TSURIMA project, takes little note of the agency of social actors will provide a governing body with little incentive to let individuals and organisations participate in disaster prevention, mitigation, or reconstruction. It is important to note that the issues outlined here about the political filtering of the conceptualisation, operationalisation, and institutional embedding of assessments are not limited to vulnerability studies. Similar analyses also are emerging in reference to forms of quantitative assessments in other fields, such as lifecycle analysis as a means of measuring carbon footprints in dairy production (Weiler et al., 20I4) and ecosystem service appraisals for gauging the economic benefits derived from nature (Lakerveld et al., 2015). Taken together, these indicate a pressing need for a broad critical reflection on assessments as technologies of governance.

This paper makes clear that the conceptualisation of vulnerability, risk, and disaster is not primarily an abstract discussion in a neutral academic environment, but rather is influenced by disciplinary factors across natural science, engineering, and social sciences. The case study shows that preferred repertoires, tried methods, and available expertise within research institutes and research teams affect the way in which the relationship between the biophysical and social factors of vulnerability is perceived. When it comes to such complex developmental issues, actors differ in their understanding of events and disagree about the meaning that should be attached to events and variables (Jasanoff, 2002, p. 268; Ribot, 20I4). The differences in perception of risk, for instance, are illustrated by the fact that TSURIMA differs from other models in its predictions of tsunami inundation in Figueira da Foz. Each has apparently conceptualised risk in its own way, resulting in distinctly different outcomes. The close connection between conceptual, operational, and institutional issues justifies more attention to the latter in addressing social vulnerability in assessments. Again, this is not an idiosyncrasy characterising vulnerability assessments only. Considerations of structuring data, for example, are common in any evaluations and studies of a certain size. Hinkel (2OII, p. 203) labels such considerations as 'non-substantial' because 
they are not based on knowledge or value judgements about vulnerability. This study demonstrates that methods and measuring instruments are inherently connected with the institutional politics of research organisations and therewith have a substantial effect on the conceptualisation and measurement of vulnerability.

The study argues for a more reflexive understanding and discussion of the operationalisation of a vulnerability assessment as a technology of governance. Scientists choose certain technologies and methodologies to produce their results. The TSURIMA vulnerability assessment is part of a tsunami risk research endeavour that filters social phenomena to allow for the use of particular methodologies and forms of data collection. The translation of social phenomena into numerical data reconstitutes these phenomena in a way that loses much of the original complexity of social vulnerability factors. The case study shows that the engineer-side of the TSURIMA team had dominant assumptions about vulnerability, which ultimately reconstituted vulnerability in such a way that elements of human agency and social dynamics were locked out. The choice to use GIS played an important part in this process. Given the importance of geographical data in tsunami risk management one can expect GIS applications to appear increasingly in vulnerability assessments, as well as in similar evaluations of processes that try to capture the voice of local citizens and organisations (Epstein, Pawar, and Simon, 2015). Consequently, this papers suggests further research on how GIS or other tools shape vulnerability assessments, and creative ways of integrating GIS into complex social dynamics.

Technologies are embedded in the institutional and social environments in which they are employed. Existing policies, or scientists' beliefs about these policies, influence scientists' choices in the construction of their assessments (Jasanoff and Wynne, I998). Hence this study proposes that scientists' choices in relation to the conceptualisation and operationalisation of their research can be better understood as emergent from the institutional setting of the work rather than from objective scientific rationality. The case study served to demonstrate that available research tools, organisational settings, and institutional cultures acted as steering mechanisms in the TSURIMA team's decision-making. The culture within a policy institution is such that information is selected that is easy for non-experts to digest and preferably expressed in straight numbers, resulting in a reduction in complexity and uncertainty. The TSURIMA scientists took these policy preferences into account in the creation of their vulnerability assessment. Moreover, the case study reveals that previous institutional configurations, such as existing risk management policies, influence how the technology of the vulnerability assessment is deployed. Such arrangements of technology reaffirm existing configurations, including the unequal distribution of wealth or power (Jasanoff, 2002). Wherever there is strong involvement of government departments or ministries, these institutional cultures often have country-specific characteristics, including the options of citizens to participate in these processes (Horst et al., 2007). If one translates this to the field of (social) vulnerability research, it means that one needs to be careful that vulnerability reduction strategies based on prior policy or scientific frameworks do not simply re-inscribe vulnerability rather than reduce it. 


\section{Conclusion}

Green and McFadden (2007) argue that understanding the social mediation of vulnerability assessments is necessary to develop new means of addressing vulnerability. Many vulnerability assessments are created to do exactly that: to contribute to finding new strategies for dealing with risk and disaster. Whichever strategies may emerge from vulnerability assessments, however, it remains vital to recognise that these evaluations are themselves socially mediated processes, a fact that has implications for the vulnerability reduction plans that ultimately materialise from the assessments.

The analysis of the TSURIMA project demonstrates how internal team dynamics and an objective of policy integration filtered out most social components of vulnerability, with the partial exception of those that could be quantified easily and were connected to physical indicators. In the TSURIMA case, the political filter produced an assessment with a limited conceptualisation of vulnerability in which available methodologies and research instruments had a substantial bearing on its operationalisation. This stemmed from the specific institutional embedding of the endeavour. The TSURIMA project conceptualised vulnerability from an engineering perspective and operationalised vulnerability through easily quantifiable and mappable indicators in GIS, resulting in the exclusion of complex social elements of vulnerability. This was not an a priori decision, but instead emerged from choices made about the assessment's structure such that it could not include them.

The processes concerning the political creation of vulnerability evident in the TSURIMA project probably will have long-term effects on how vulnerability is assessed and addressed in Portugal. The strict division of assessment variables into either physical or socioeconomic categories prevents effective risk management and disaster prevention because it omits the causes of risk. Oliver-Smith (I999) reasons that separating physical from socioeconomic variables in evaluating vulnerability is equal to separating cause and effect, since it means separating hazards from disasters. By extension, this process removes vulnerability from the discussion of disaster and risk and the question concerning 'why' a disaster occurred cannot be asked. A related effect of the TSURIMA methodology is the recreation of vulnerability in any postdisaster reconstruction (Comfort et al., I999). The focus on the physical element of vulnerability means that reconstruction policy will emphasise this element without considering the environmental, institutional, social, or technical factors that led to this element's vulnerability. Moreover, local experts and citizens are excluded from playing any part in vulnerability reduction strategies when assessments do not assign any agency or individual risk management capacity to non-scientific actors. Phenomena related to social organisation, learning, innovation, or social capital probably will be missing from policies based on this type of research.

Since vulnerability assessments often are specifically designed to contribute to policy, they offer an interesting perspective on the mutually constitutive relationship between science and policy. Acting as technologies of governance, they sustain and reinforce existing forms of study of risk and dealing with disaster. They may well re-inscribe patterns of organisation and practice among scientists, policymakers, and 
citizens that cause vulnerability, instead of breaking down these patterns. This paper has shown that vulnerability assessments are not straightforward, neutral, and universal tools in disaster management. Rather, they are prone to internal and political forces that determine the content and outcome of the evaluation, which in turn has implications for disaster policy based on the assessment.

\section{Correspondence}

Dr Harro Maat, Assistant Professor, Knowledge, Technology and Innovation Group, Wageningen University, P.O. Box 8I30, 6700 EW Wageningen, the Netherlands. E-mail: harro.maat@wur.nl

\section{Endnotes}

I Q Methodology is used to examine how people think about a certain topic, such as tsunami risk (ISSSS, 20I I). Participants rank statements in a procedure called 'Q Sort' (Previte, Pini, and HaslamMcKenzie, 2007).

\section{References}

Barros, J.L., A.O. Tavares, A. Santos, and A. Fonte (2015) 'Territorial vulnerability assessment supporting risk managing coastal areas due to tsunami impact'. Water. 7(9). pp. 497I-4998.

Birkmann, J. (2006) 'Measuring vulnerability to promote disaster-resilient societies: conceptual frameworks and definitions'. In J. Birkmann (ed.) Measuring Vulnerability to Natural Hazards. UNU Press, Tokyo. pp. 9-54.

Birkmann, J., K. von Teichman, T. Welle, M. González, and M. Olabarrieta (20ı) 'The unperceived risk to Europe's coasts: tsunamis and the vulnerability of Cadiz, Spain'. Natural Hazards and Earth System Sciences. IO(I2). pp. 2659-2675.

Birkmann, J. et al. (20I3) 'Framing vulnerability, risk and societal responses: the MOVE framework'. Natural Hazards. 67(2). pp. I93-2II.

Chester, D.K. and O.K. Chester (20IO) 'The impact of eighteenth century earthquakes on the Algarve region, southern Portugal'. Geographical Journal. I76(4). pp. 350-370.

Comfort, L. et al. (I999) 'Reframing disaster policy: the global evolution of vulnerable communities'. Environmental Hazards. I(I). pp. 39-44.

Cutter, S.L. (20I I) 'A ciência da vulnerabilidade: modelos, métodos e indicadores'. Revista Crítica de Ciências Sociais. 93(I). pp. 59-69.

Cutter, S.L. (2013) 'Vulnerability'. In P.T. Bobrowsky (ed.) Encyclopedia of Natural Hazards. Springer, Dordrecht. pp. Io88-IO90.

Cutter, S.L., B.J. Boruff, and W.L. Shirley (2003) 'Social vulnerability to environmental hazards'. Social Science Quarterly. 84(2). pp. 242-26I.

Daniels, R.S. (2013) 'The rise of politics and the decline of vulnerability as criteria in disaster decisions of the United States, I953-2009'. Disasters. 37(4). pp. 669-694.

Delaney, A., S. Chesterman, T.A. Crane, P.A. Tamás, and P. Ericksen (20r4) A Systematic Review of Local Vulnerability to Climate Change: In Search of Transparency, Coherence and Comparability. CCAFS Working 
Paper. No. 97. https://ccafs.cgiar.org/publications/systematic-review-local-vulnerability-climate-changesearch-transparency-coherence-and\#.WBuN3_krKUk (last accessed on 3 November 20I6).

Douglas, M. (1986) How Institutions Think. Syracuse University Press, Syracuse, NY.

Eckert, S., R. Jelinek, G. Zeug, and E. Krausmann (2012) 'Remote sensing-based assessment of tsunami vulnerability and risk in Alexandria, Egypt'. Applied Geography. 32(2). pp. 714-723.

Epstein, C., A. Pawar, and S.C. Simon (2015) Emergency Management and Social Intelligence; A Comprehensive All-hazards Approach. CRC Press, Boca Raton, FL.

Fuchs, S. (2009) 'Susceptibility versus resilience to mountain hazards in Austria - Paradigms of vulnerability revisited'. Natural Hazards Earth System Science. 9(2). pp. 337-352.

Fuchs, S., J. Birkmann, and T. Glade (2012) 'Vulnerability assessment in natural hazard and risk analysis: current approaches and future challenges'. Natural Hazards. 64(3). pp. 1969-1975.

Green, C. and L. McFadden (2007) 'Coastal vulnerability as discourse about meanings and values'. Journal of Risk Research. Iо(8). pp. I027-1045.

Hinkel, J. (2OI I) "Indicators of vulnerability and adaptive capacity": towards a clarification of the science-policy interface'. Global Environmental Change. 2I(I). pp. 198-208.

Horst, M., A. Irwin, P. Healey, and R. Hagendijk (2007) 'European scientific governance in a global context: resonances, implications and reflections. IDS Bulletin. pp. 38(5). pp. 6-20.

Instituto Nacional de Estatística (20 I I) 'Censos 20 I : Resultados definitivos'. http://www.ine.pt/ scripts/flex_definitivos/Main.html (last accessed on 3 November 20II).

ISSSS (International Society for the Scientific Study of Subjectivity) (20I I) 'Welcome to qmethod.org'. http://qmethod.org/about (last accessed on I4 November 20I6).

Jasanoff, S. (1999) 'The songlines of risk'. Environmental Values. 8(2). pp. I35-I52.

Jasanoff, S. (2002) 'New modernities: reimagining science, technology and development'. Environmental Values. II (3). pp. 253-276.

Jasanoff, S. and B. Wynne (1998) 'Science and decisionmaking'. In S. Rayner and E.L. Malone (eds.) Human Choice and Climate Change. Volume I. Batelle Press, Columbus, OH. pp. I-77.

Lakerveld, R.P., S. Lele, T.A. Crane, K.P.J. Fortuin, and O. Springate-Baginski (2015) 'The social distribution of provisioning forest ecosystem services: evidence and insights from Odisha, India'. Ecosystem Services. I4 (August). pp. 56-66.

MAOTDR (Ministério do Ambiente; do Ordenamento do Território e do Desenvolvimento Regional) (2007) GIZC: Bases para a Estratégia de Gestão Integrada da Zona Costeira Nacional. Ministério do Ambiente; do Ordenamento do Território e do Desenvolvimento Regional, Lisbon.

McLaughlin, S. and J.A.G. Cooper (20I0) 'A multi-scale coastal vulnerability index: a tool for coastal managers?'. Environmental Hazards. 9(3). pp. 233-248.

Mendes, J.M. (2009) 'Social vulnerability indexes as planning tools: beyond the preparedness paradigm'. Journal of Risk Research. I2(I). pp. 43-58.

Nelson, D.R., W.N. Adger, and K. Brown (2007) 'Adaptation to environmental change: contributions of a resilience framework'. Annual Review of Environment and Resources. 32 (November). pp. 395-4I9.

Nunes, J.A. and M. Matias (2004a) Agonistic Spaces, Contentious Politics and the Trials of Governance: Environmental Policies and Conflict in Portugal. STAGE (Science, Technology and Governance in Europe) Discussion Paper. No. 2I. Centro de Estudos Sociais, Coimbra.

Nunes, J.A. and M. Matias (2004b) Science, Technology and Governance in Portugal. STAGE (Science, Technology and Governance in Europe) Discussion Paper. No. 22. Centro de Estudos Sociais, Coimbra. Oliver-Smith, A. (1999) “'What is a disaster?”: Anthropological perspectives on a persistent question'. In A. Oliver-Smith and S.M. Hoffman (eds.) The Angry Earth: Disaster in Anthropological Perspective. Routledge, New York, NY. pp. I8-34.

Oliver-Smith, A. (2004) 'Theorizing vulnerability in a globalized world: a political-ecological perspective'. In G. Bankoff, G. Frerks, and D. Hilhorst (eds.) Mapping Vulnerability: Disasters, Development and People. Earthscan, London. pp. IO-24 
Oliver-Smith, A. (2005) 'Communities after catastrophe'. In S.E. Hyland (ed.) Community Building in the Twenty-First Century. School of American Research Press, Santa Fe, NM. pp. 45-70.

Papathoma, M. and D. Dominey-Howes (2003) 'Tsunami vulnerability assessment and its implications for coastal hazard analysis and disaster management planning, Gulf of Corinth, Greece'. Natural Hazards and Earth System Sciences. 3(6). pp. 733-747.

Papathoma, M., D. Dominey-Howes, Y. Zong, and D. Smith (2003) 'Assessing tsunami vulnerability, an example from Herakleio, Crete'. Natural Hazards and Earth System Sciences. 3(5). pp. 377-389.

Porter, T.M. (I995) Trust in Numbers: The Pursuit of Objectivity in Science and Public Life. Princeton University Press, Princeton, NJ.

Previte, J., B. Pini, and F. Haslam-McKenzie (2007) 'Q methodology and rural research'. Sociologia Ruralis. 47(2). pp. I35-I 47.

Ribot, J. (2014) 'Cause and response: vulnerability and climate in the Anthropocene'. The Journal of Peasant Studies. 4I(5). pp. 667-705.

Schmidt, L., P. Prista, T. Saraiva, T. O'Riordan, and C. Gomes (20I3) 'Adapting governance for coastal change in Portugal'. Land Use Policy. 3 I (March). pp. 3I4-325.

Universidade de Coimbra and Câmara Municipal da Figueira da Foz (20Io) Plano Municipal de Emergência de Protecção Civil. Faculdade de Letras da Universidade de Coimbra-Centro de Estudos de Geografia e Ordenamento do Território, Figueira da Foz.

Weichselgartner, J. (200I) 'Disaster mitigation: the concept of vulnerability revisited'. Disaster Prevention and Management. Io(2). pp. 85-95.

Weiler, V., H.M.J. Udo, T. Viets, T.A. Crane, and I.J.M. De Boer (20I4) 'Handling multi-functionality of livestock in a life cycle assessment: the case of smallholder dairying in Kenya'. Current Opinion in Environmental Sustainability. 8. pp. 29-38.

Wisner, B., P. Blaikie, T. Cannon, and I. Davis (2004) At Risk: Natural Hazards, People's Vulnerability and Disasters. Second edition. Routledge, New York, NY. 